Cornell Law Library

Scholarship@Cornell Law: A Digital Repository

Cornell Law Faculty Publications

Faculty Scholarship

4-1-2003

\title{
Jurors' Evaluations of Expert Testimony: Judging the Messenger and the Message
}

Sanja Kutnjak Ivkovic

Valerie P. Hans

Cornell Law School, valerie.hans@cornell.edu

Follow this and additional works at: http://scholarship.law.cornell.edu/facpub

Part of the Evidence Commons, and the Litigation Commons

\section{Recommended Citation}

Ivkovic, Sanja Kutnjak and Hans, Valerie P., "Jurors' Evaluations of Expert Testimony: Judging the Messenger and the Message" (2003). Cornell Law Faculty Publications. Paper 385.

http://scholarship.law.cornell.edu/facpub/385

This Article is brought to you for free and open access by the Faculty Scholarship at Scholarship@Cornell Law: A Digital Repository. It has been accepted for inclusion in Cornell Law Faculty Publications by an authorized administrator of Scholarship@Cornell Law: A Digital Repository. For more information, please contact jmp8@cornell.edu. 


\title{
Jurors' Evaluations of Expert Testimony: Judging the Messenger and the Message
}

\author{
Sanja Kutnjak Ivković \\ Valerie P. Hans
}

Jurors are laypersons with no specific expert knowledge, yet they are routinely placed in situations in which they need to critically evaluate complex expert testimony. This paper examines jurors' reactions to experts who testify in civil trials and the factors jurors identify as important to expert credibility. Based on in-depth qualitative analyses of interviews with 55 jurors in 7 civil trials, we develop a comprehensive model of the key factors jurors incorporate into the process of evaluating expert witnesses and their testimony. Contrary to the frequent criticism that jurors primarily evaluate expert evidence in terms of its subjective characteristics, the results of our study indicate that jurors consider both the messenger and the message in the course of evaluating the expert's credibility.

In an insightful review of the use of expert evidence in litigation, University of Michigan Law Professor Samuel Gross outlined the "essential paradox" of expert testimony: "We call expert witnesses to testify about matters that are beyond the ordinary understanding of lay people (that is both the major practical justification and a formal legal requirement for expert testimony), and then we ask lay judges and jurors to judge their testimony" (1991, 1182).

How does a layperson cope with the challenge? Some of the sharpest

\footnotetext{
Sanja Kutnjak Ivković is assistant professor, Florida State University, School of Criminology and Criminal Justice. Valerie P. Hans is professor, University of Delaware, Department of Sociology and Criminal Justice. This article is based on research funded by National Science Foundation grants SES-8822598 and GER-9350498 to Valerie P. Hans. The authors wish to express their gratitude to Kathleen Tierney for her assistance with the qualitative analysis. An early account of some of the findings reported herein appeared in Advocate 16(4) in 1999, pp. 17-21, and is reprinted by permission.
} 
attacks on the jury as an institution center on jurors' difficulties with expert evidence. Popular commentator Peter Huber's argument that the courts have fallen victim to "junk science" (1991) is based on his view that when juries and credulous judges attempt to evaluate expert scientific testimony in the courtroom, many are unable to separate sound science from fanciful fiction. The result: huge awards that are said to be based more on the jury's sympathy than on credible scientific evidence linking a defendant's actions or products to a plaintiff's injuries. Few jury scholars would go so far as Huber to agree that jurors are unable to evaluate scientific evidence (see Cecil, Hans, and Wiggins 1991; Brief Amici Curiae 1998). But surveys of judges and jurors themselves indicate that jurors find the task of evaluating expert evidence to be challenging.

The question of juror understanding of expert evidence has aroused a great deal of interest in the legal community. Litigators often present key trial evidence through expert witnesses. These experts are given wide latitude in their testimony, and their ability to convey complex points to a jury can make or break a case. Aside from their own experiences, hunches, and intuitions, trial lawyers have limited systematic information available to predict how the jury will receive expert evidence.

Standards of admissibility of expert testimony also rely on unexamined premises about how jurors respond to expert witnesses. The United States Supreme Court has concluded that trial judges should act as gatekeepers of expert testimony, making preliminary scientific evaluations before allowing an expert to testify in the presence of the jury (Daubert v. Merrell Dow Pharmaceuticals, 509 U.S. 579 [1993]; General Electric v. Joiner, 522 U.S. 136 [1997]; Kumho Tire v. Carmichael, 526 U.S. 137 [1999]). One key assumption underlying the Daubert line of cases is that jurors might be duped by a persuasive but untrustworthy expert who testifies about matters that are not based on sound scientific principles or data.

Social scientists have begun to study laypersons' responses to expert testimony. Given the public debate, it is not surprising that much of the work is focused on how well jurors are able to understand expert testimony. In addition, projects using jury simulation methodology have explored how mock jurors react to expert testimony about, for example, statistical evidence, the battered woman syndrome, or factors affecting eyewitness identification. However, there has been less work on jurors' reactions to the most common types of expert evidence, such as medical testimony and economic evidence. In addition, relatively few studies to date have examined in detail how real jurors respond to real experts in the context of real trials.

This article presents new information about how jurors respond to expert witnesses and their testimony. The article fills some of the gaps in prior research by examining the jurors' reactions to experts who testified in actual civil trials. In our analysis of transcripts of semi-structured interviews with actual jurors, we employ systematic qualitative methodology to develop a 
comprehensive model of the key factors that jurors consider as they assess experts and expert testimony. We conclude that both the characteristics of the expert (the "messenger") and the substantive and stylistic aspects of the testimony itself (the "message") contribute significantly to the overall impact of expert testimony on jurors.

\section{WHAT DO WE KNOW ABOUT JURORS' REACTIONS TO EXPERTS AND EXPERT TESTIMONY?}

Before describing our own study, we will assess what we already know about jurors' evaluation of expert witnesses and expert testimony. Much of the existing research is focused around the question of whether jurors are competent to critically assess and evaluate the claims and technical information provided by experts.

In their sample of criminal jury trials from the 1950s, Kalven and Zeisel (1966) found that experts testified relatively infrequently. Just one case in four included an expert, typically a medical doctor and usually a prosecution expert witness (Kalven and Zeisel 1966, 139-40, tables 37 and 38). Analyzing questionnaires from the judges presiding over jury trials, Kalven and Zeisel found just one case, an embezzlement trial of a city bookkeeper that included expert testimony about bookkeeping, in which the judge stated that the jury's verdict was linked to its inability to understand the case. The jurors were all poorly educated, according to the judge, and "the jury simply was not able to understand the case" (Kalven and Zeisel 1966, 152-53). In the judge's eyes, the defendant's expert witness presented testimony that "bordered on perjury," and he was charged with disciplinary action at the time of the trial, a damaging fact that the judge knew but the jury did not (1966, 153 n.7).

Compared to jurors from the 1950 s, jurors today face more scientific and technical evidence presented through expert testimony. In contemporary criminal cases, experts testify in a sizeable minority of felony trials (Gross 1991). Civil cases, on the other hand, appear to include a greater number of experts. Samuel Gross analyzed the frequency of appearances by experts in 529 California civil jury trials in the mid-1980s and discovered that they testified in the vast majority $(86 \%)$ of them, with an average of 3.3 experts per trial. The greatest frequency of experts was in personal injury trials, especially medical malpractice and product liability (Gross 1991). The Rand Corporation's Institute for Civil Justice compiled a larger data set of 6,573 California civil trials from 1980 to 1985 . In the cases covered by the Rand data set, experts testified at the rate of 3.7 experts per trial (Gross 1990; Gross and Syverud 1996).

The Federal Judicial Center undertook surveys of U.S. district court judges and attorneys during the 1990s to obtain information about the use 
of expert testimony in federal trials pre- and post-Daubert (Krafka et al. 2002). Judges reported information on their most recent trial involving expert witnesses. Trials with experts averaged three experts per case in 1991; by 1998 the average was 4.1 . Across the multiple surveys, about $40 \%$ of the experts were in medicine or mental health; $25 \%$ possessed business, financial, or legal specialties; a similar number specialized in engineering/process/ safety; and the remainder had other scientific specialties. The single most frequent type of expert was an economist, accounting for $11 \%$ of all experts testifying in these federal trials.

Is jury comprehension detrimentally affected by the large quantity of expert testimony or the increased complexity of the testimony that juries must evaluate? Goodman, Greene, and Loftus (1985) interviewed judges and jurors about problems jurors face in complex cases. When jurors had difficulty, judges most frequently pointed to problems in understanding the evidence, especially expert testimony. Conflicting expert testimony from highly qualified medical witnesses was seen as particularly difficult for jurors. The authors outlined several possible approaches that jurors might take to resolve conflicting expert testimony. One was to ignore all expert testimony and evaluate the case on other grounds. In their interviews with jurors, the authors found that this was rare. Jurors were more likely to try to unravel the factors leading to the contradictory testimony, or to reach their own conclusions about the content of the testimony. In some cases they also made judgments about which expert was the most credible and relied on that expert's testimony. For example, in an asbestos case, one expert impressed jurors because of his credentials and prominent position in the field. The authors observed that, it seems that "jurors in product cases often make these kinds of judgments-personal judgments about the experts and not about the information relayed" (Goodman et al. 1985, 68).

The American Bar Association Special Committee of Jury Comprehension (1989) undertook an in-depth study of jury decision making in four highly complex cases, three of which included expert evidence. Judges, jurors, and attorneys in those cases were interviewed, a questionnaire was distributed to jurors, alternate jurors were formed into mock juries, and their deliberations were videotaped. Jurors rejected experts who seemed to be hired guns, and accepted as the most influential those who tended to be directly involved with the parties (such as a personal physician) and those who presented understandable testimony.

Two additional case studies focused on jurors' understanding of expert evidence, their attitudes toward the experts, and the potential impact experts had on decision making. Rand Corporation researchers Selvin and Picus (1987) observed a complex tort trial in Texas and interviewed the six-member jury at the end of the trial. The researchers reported that the jury's recollection and understanding of specific scientific and medical facts in the case contained several errors (e.g., the jury did not understand the 
relationship between smoking and the development of breathing problems experienced by the plaintiffs), which led jurors to discard the testimony of the medical experts who had testified on this point. Selvin and Picus concluded that "[c]onfronted with so much complex and confusing information, the jurors tended to evaluate the credibility of these witnesses in large part on their personal characteristics rather than on the information they presented" $(1987,27)$.

In another complex tort case, Sanders (1993) conducted posttrial interviews with four out of twelve jurors. When asked to rate the experts in the case, jurors expressed contradictory views and had problems distinguishing among the experts. They also discounted the expert opinion in the case as the product of hired guns. Sanders reported that jurors seemed bored and confused by the epidemiological evidence, which minimized its impact on the jurors, and the three conflicting epidemiologists canceled each other out. However, one expert caught their attention and received highly positive evaluations because of his "pretty impressive" and "real good explanation" (Sanders 1993, 62).

In contrast to work focusing predominantly on the competence of jurors to understand expert testimony, Shuman, Champagne, and Whitaker have undertaken a more comprehensive look at juror reactions to experts (Champagne, Shuman, and Whitaker 1992; Shuman and Champagne 1997; Shuman, Champagne, and Whitaker 1996a, 1996b; Shuman, Whitaker, and Champagne 1994). In a series of opinion surveys and other studies, the authors examined the range of factors that may affect juror reactions to experts. The response rates were generally low in these studies, but the results are intriguing. Although the majority of lawyers and experts surveyed by Shuman and his colleagues expressed some confidence in the jury's ability to understand expert testimony, they typically saw jurors as less capable than judges when it came to evaluating it (Shuman et al. 1994). The experts emphasized that jurors placed more importance on personality and physical attractiveness in assessing expert credibility than did judges (Shuman et al. 1994). Here, the experts follow the tradition of believing that jurors are much more susceptible to various biases compared to judges, who are seen as being able to rise above human prejudices (but see Guthrie, Rachlinski, and Wistrich 2001; Landsman and Rakos 1994).

The majority of jurors who participated in the surveys agreed that expert testimony was crucial to the outcome of their cases (Champagne et al. 1992). In contrast to the experts' perceptions, however, very few jurors reported that an expert's pleasant personality or physical appearance influenced their decision (Champagne et al. 1992; Shuman et al. 1994). Rather, they emphasized the expert's ability to convey technical information nontechnically, the expert's willingness to draw firm conclusions, the expert's reputation as a leading expert, and the expert's impressive educational credentials as more influential (Champagne et al. 1992; Shuman et al. 1994). 
Shuman et al. (1994) concluded that the expert's field and occupation and jurors' demographic characteristics had no significant role in assessments of experts' credibility. On the other hand, the party who retained the expert was important, as was the expert's qualifications, familiarity with the case, quality of reasoning, and impartiality.

In addition to these general surveys or assessments of jurors and expert testimony, a number of studies focus on the use of experts in particular types of trials. Vidmar, for example, studied jury performance in North Carolina medical malpractice cases. On the basis of postdeliberation interviews with jurors, he concluded that they "come to understand the adversary system and on the whole evaluate expert witnesses in the light of this perspective" (Vidmar 1995, 173). Thus, they raised questions about the objectivity of experts who were hired guns or were close colleagues of the defendants, and they discussed possible motives of experts in other cases. Jurors also tried to understand the content of the testimony. In one case, once lawyers and experts explained the issues, four out of seven jurors interviewed "appeared to clearly understand the technical evidence" (Vidmar 1994, 903). However, some jurors tended to rely on general impressions over the content of the testimony, and "when there are competent experts on both sides, and they offer contradictory or confusing opinions, jurors may resolve the differences by relying on general impressions of character and veracity" (Vidmar 1995, 172).

Jury simulation studies offer another approach to examining juror reactions to expert testimony (Vidmar and Diamond 2001). Jacoubovitch et al. (1977) examined the effect on jurors of direct testimony from an expert versus mediated testimony, in which an attorney read the expert's testimony verbatim. Respondents in the direct-testimony condition evaluated experts as more confident and competent, and reported having a clearer impression of the expert than did the respondents in the mediated-testimony condition. DeWitt, Richardson, and Warner (1997) further studied the impact of the source of expertise on mock jurors' perceptions and decision making. In an experiment involving novel scientific evidence, participants were persuaded by unreliable evidence that would fulfill neither the Frye test nor the Daubert criterion (DeWitt et al. 1997).

Lawyer tactics or "dirty tricks" of cross-examination may affect evaluations of an expert's credibility. Kassin, Williams, and Saunders (1990) found that a question during the cross-examination in a simulated rape trial implying something negative about the reputation of the expert, although uncorroborated by other evidence and even denied, diminished the credibility of an expert witness. In contrast, Kovera et al. (1994) reported in their experimental study of a child sexual abuse case that the strength of crossexamination was unrelated to the credibility of the expert witnesses. Furthermore, their study yielded important results with respect to the different types of expert evidence (syndrome, witness credibility, and anatomically 
detailed dolls) used in a child sexual abuse case. In particular, although expert evidence had an impact on the mock jurors' judgments regardless of type, syndrome evidence (probabilistic in nature) was less likely to be recalled than either of the two other types of expert evidence, was evaluated as less important and less helpful, and was found to result in less positive ratings of the expert and her testimony.

Other mock studies have evaluated the impact of various types of expert testimony on jurors' opinions. Diamond and Casper (1992) presented jurors with several videotape versions of an antitrust price-fixing case varying between the statistical model and the concrete yardstick model of expert testimony. Jurors did not perceive either model as more persuasive than the other, but they viewed the statistical expert as having greater expertise while being less clear. The positive and negative characteristics neutralized each other, however, so neither expert outdid the other when the jury rated the plaintiff and defense cases nor when they awarded damages.

Juror comprehension of statistical or probabilistic evidence, undoubtedly among the most complex and difficult expert evidence, was a topic of several other studies. Thompson and Schumann (1987) examined how mock jurors evaluate statistical evidence in criminal cases. They concluded that the respondents were susceptible to fallacious statistical reasoning, and had difficulty detecting flaws in arguments based on statistics. In their studies, mock jurors often underestimated or overestimated the value of statistical evidence. Several other mock juror studies show that mock jurors may underutilize statistical experts (Faigman and Baglioni 1998; Smith et al. 1996; Schklar and Diamond 1999).

Another set of jury simulation studies focused on experts who testified about battered woman syndrome or rape trauma syndrome. Brekke and Borgida (1988) found that when two opposing experts on rape trauma syndrome presented evidence, mock jurors' responses were similar to the condition when no expert testimony was presented, suggesting that jurors may resolve the issue of conflicting testimonies by ignoring both of them (and resorting to their prior belief) or by accepting the one that supports their prior belief. Studies by Follingstad et al. (1989) and Finkel, Meister, and Lightfoot (1991) reached a similar conclusion: Presence of an expert on battered woman syndrome did not alter the verdict reached by mock jurors in criminal cases, but it did influence the way jurors perceived the case. By contrast, Schuller's studies found that expert evidence altered jurors' evaluations of the defendant's perceptions and resulted in greater leniency in their verdicts (Schuller 1990; Schuller and Vidmar 1992).

Cooper and his colleagues (Cooper, Bennett, and Sukel 1996) explored the importance of testimony's complexity by varying its complexity and the strength of the experts' credentials. They found that personal characteristics of the experts, such as their credentials, played a significant role only when the evidence was complex and the mock jurors had difficulty evaluating it. 
Cooper et al. (1996) hypothesized that mock jurors confronted with difficult testimony would shift from central processing of the evidence, which involves careful critical analysis of the content and quality of the argument, toward peripheral processing, in which jurors rely on shortcuts and heuristics to assess the validity of the testimony. Cooper and Neuhaus (2000) undertook three additional experiments to examine that hypothesis. In the first, mock jurors who heard testimony of a highly paid expert with high credentials-potentially fitting the profile of a hired gun - rated the expert as less likable, less believable, less trustworthy, less honest, and more annoying, compared to the mock jurors in any of the remaining three conditions (experts with low pay, high credentials; low pay, low credentials; high pay, low credentials). In a second study, Cooper and Neuhaus varied the pay and the frequency of testimony by an expert with high credentials. Mock jurors showed more trust in the novice experts than in the experts who testified frequently. In particular, they were the least convinced by, and least likely to trust, the experienced expert with high pay. The third in the series of experiments examined the effect of the pay and the complexity of testimony on the mock jurors' perceptions of trustworthiness and believability of a frequently testifying expert with high credentials. The results suggest a significant interaction between the pay and the complexity of testimony. While in the case of simple testimony the expert's pay induced no differences in the degree of expert's trustworthiness, when the testimony was complex, the expert who received the highest pay was evaluated as the least trustworthy. Cooper and Neuhaus concluded that jurors shifted from central to peripheral processing under cognitively challenging conditions. However, Vidmar and Diamond (2001) offer the alternative explanation that mock jurors may have centrally processed the testimony but rejected it when the expert's motives were suspicious and the testimony was interpreted as purposefully confusing.

Opinions about expert witnesses may be affected not only by respondents' trial experiences, but also by their out-of-court experiences with experts of a particular type (e.g., physicians, economists; Saks and Wissler 1984) and their life experiences in general. In surveys of the public, expert witnesses (together with the police) were rated as the least dishonest and the most confident, likable, and believable of the witnesses in the trials (i.e., defendants, victims, eyewitnesses; Linz and Penrod 1982). Respondents' educational level did not affect their ratings of experts' honesty, but it did affect ratings of their competence (Linz and Penrod, 1982); more educated jurors were less likely to believe an expert.

Two experimental studies examined the effect of gender on the perceptions of the experts' believability. Vondergeest, Honts, and Devitt (1993) found no effect of either the expert's gender or the juror's gender on the verdict. Similarly, Memon and Shuman (1998) reported no differences in jurors' perceptions of female versus male expert witnesses, nor did ratings 
of experts provided by female and male jurors differ significantly. Although the researchers reported that evaluations of an expert's reasoning and objectivity were not influenced by the expert's race and gender, they found an interaction effect of gender and race on perceptions of the expert's believability. For example, contrary to their expectations, a black female expert was evaluated as the most believable (Memon and Shuman 1998).

This review of existing research indicates that only a modest number of studies have examined actual jurors' reactions to experts. Moreover, these studies with actual jurors typically have included only one or a very few cases. In addition, the literature on the whole has focused on a small subset of types of cases, such as complex cases or medical malpractice trials. Some of the studies that have obtained the reactions of actual jurors have suffered from relatively low response rates of $20 \%$ or $30 \%$, which raises questions about potential selection bias and imperils generalization of the results. Furthermore, the use of structured, quantitative methodology does not allow the respondents to explain the issues; rather, it restricts respondents' answers to the offered ones.

While providing important insights into the phenomenon of expert testimony and its impact on jurors, mock jury research takes place in a controlled environment, and it typically uses only one or two experts in each study. The differences between the conditions in mock jury research (e.g., complex and simple testimony, high and low credentials) are seldom so exaggerated in real life. Depending on the study design, mock jurors, unlike actual jurors, may make individual decisions, may not engage in group deliberation, may not see and hear experts in person, may receive no judicial instructions, and lack the overall sense of finality that accompanies a verdict and the pressures and motivations associated with real jury service. Samples are relatively small and the subjects used in such studies-often college students-have frequently been nonrepresentative of typical jury pools in terms of age, education, class, race, and experience.

Further, the studies to date have tended to focus on a limited range of expertise. While the effects of psychological experts, such as those testifying about battered women or eyewitnesses, have been examined frequently, the more mundane (but more common) medical experts in actual trials have received considerably less attention. For instance, in the Gross data set, psychological experts comprised $3 \%$ of all expert witnesses; in the Rand study, that figure was $4 \%$. In contrast, medical doctors constituted respectively $49 \%$ and $56 \%$ of the Gross and Rand cases (Gross 1991). Medical experts account for about half the experts in federal trials (Krafka et al. 2002). Although this issue has not yet been extensively explored, jurors may respond quite differently to expert psychological claims about human behavior, which they may feel they are more able to judge independently, than to medical or economic testimony (Shuman et al. 1996b), so the overemphasis on psychological testimony may be misleading. Furthermore, crim- 
inal and civil cases present somewhat different environments for expert witnessing, and there is a need to explore both domains. For example, Casper and Diamond (1993) have observed that strong values that jurors bring to death penalty cases may limit the range of potential impact of an expert, whereas in civil trials involving matters like antitrust, their values may be less significant.

This article presents a detailed model of how jurors respond to a range of expert witnesses through an in-depth qualitative analysis of interviews with actual jurors. As part of a larger study of juries in business and corporate civil cases (Hans 2000), we had available a large number of transcripts of semi-structured interviews with civil jurors. Among other information, jurors provided in their own words the reactions they had to experts who testified in the real cases they decided.

In this article we examine the jurors' impressions and comments on a range of expert witnesses in a number of cases, and whenever possible, we contrast and compare opinions of jurors who evaluated the credibility of the same expert in the case. By analyzing interviews from civil jurors in business tort and medical malpractice cases, we attempt to determine what factors jurors take into account in assessing the credibility of the expert. Using these factors in a systematic way, we provide a model of expert witness credibility. The results suggest that jurors are affected by both the personal characteristics of the expert (the messenger) and by the substantive and stylistic aspects of the expert testimony (the message).

\section{RESEARCH METHOD}

\section{Cases and Participants}

This study of jurors' evaluations of experts, based primarily on a total of 55 tape-recorded interviews, is part of a larger interview study examining the reactions of 269 jurors in cases with business and corporate parties (Hans 2000). The researchers identified every civil jury trial that involved a business or corporate party during a one-year period in a state court of general jurisdiction. Jurors from these trials were contacted, and those who agreed to participate in the study were interviewed about how they reached a decision in the case. The overall response rate of the jurors was $64 \%$, with an average of 7 out of 12 jurors on each case participating in the study. Two questions specifically tapping attitudes about experts were included in a postinterview questionnaire completed by all 269 jurors. We report the data below.

In addition, to examine jurors' evaluations of experts in depth and detail, we selected seven cases from the total of 36 cases, involving a total of 55 jurors, for further analysis of interview transcripts. We wanted to undertake concentrated qualitative analysis of each of the juror's comments about ex- 
perts, and thus needed to limit our inquiry to a smaller number of transcripts. Further, since contract disputes are less likely to include expert testimony (Gross 1991), we decided to exclude them from our analysis. Finally, we were particularly interested in how jurors dealt with conflicting expert testimony, and so selected cases in which more experts, and opposing experts, had testified.

This final set of seven cases included two medical malpractice cases, two workplace injury cases, a product liability case, an asbestos case, and a motor vehicle accident case. All cases included a corporate defendant. In every trial, both sides presented expert witnesses. The total number of experts in the cases was 33; the number of experts in each case ranged from 3 to 6 , with an average of 4.7 . The vast majority of the experts ( 25 of 33 ) were physicians. The remaining experts were a physical therapist, a laboratory technician, two architects, an engineer, and three economists. The total number of jurors in the seven cases was 55 . Although not every juror commented on every expert who testified at his or her trial, the total number of potential juror-expert observations represented by our sample is 256 .

\section{Procedure}

Jurors were interviewed individually using a semi-structured interview format that took about an hour to complete. They were asked to give their reactions to the parties, attorneys, and evidence in the case; to answer a series of questions about how they decided the verdict and any award; and to discuss the factors that affected their decision. They then completed a questionnaire that tapped general attitudes toward litigation, business, and responsibility. Two questions about experts appeared on this questionnaire.

A list of witnesses, including expert witnesses, was obtained from public records, and was shown to each juror during the interview. Jurors were asked to go through the list and summarize the testimony and their reactions to each witness, especially if he or she provided what the juror considered to be important testimony. Typical follow-up questions and probes included, "What did he [the expert] have to say?" "In what way did that affect you?" "What is your impression of her?" "Did that influence his credibility?" "Were the experts for the plaintiff or the experts for the defendant more credible?" "Was any of the evidence she [the expert] presented difficult to understand?"

Due to the semi-structured format of the interview, the wording of questions sometimes varied, and different probes were used depending on the nature of the case, the testimony, and the juror. Most comments about expert witnesses were made during this "list of witnesses" portion of the interview, but comments about expert testimony were also made at later points as well. We reviewed the entire interview transcript to ensure that all comments about experts were included in our analysis. 
To determine which witnesses listed in the public record were experts, we relied on the definition provided in Federal Rule of Evidence 702 and the collective reports of the jurors in a particular case. Because the witness lists contained errors, as we discovered in interviewing the jurors, we relied on the interviews rather than the public records for our final classification of a witness as an expert. We did not require that a person have an advanced degree to be considered an expert, although if a witness was listed as an M.D. or a Ph.D., that eased our task of locating the experts. We used juror interviews to determine which witnesses provided special expert knowledge on the subject matter of the lawsuit and thus should be identified as experts. Of course, medical doctors who were defendants were not counted as experts, even though their testimony was at times complex and technical.

Experts who testified in these cases were mostly men (31 out of 33). We inferred that the large majority of experts were Caucasian, on the basis of jurors' comments and experts' last names. Only one expert witness was identified by jurors as African American; another was described as foreign.

\section{ANALYSIS}

\section{Questionnaire Responses}

Responses of the full sample of 269 jurors to the two questionnaire items about experts are displayed in table 1 . The responses to these items should alleviate concerns that citizens enter the jury box prone to unquestioning acceptance of expert evidence. Instead, a good deal of skepticism about experts is shown in the jurors' responses to the two items from the questionnaire. For example, seven of ten jurors either agreed or strongly agreed with the statement that "lawyers can always find an expert who will back up their client's point of view, no matter what it is." Just one of every ten jurors disagreed with this statement. At the very least, the jurors' responses contradict the idea

\section{TABLE 1}

Jurors' Views of Experts

\begin{tabular}{lccccc}
\hline & $\mathrm{SA}$ & $\mathrm{A}$ & $\mathrm{N}$ & $\mathrm{D}$ & $\mathrm{SD}$ \\
$\mathbf{( \% )}$ & $\mathbf{( \% )}$ & $\begin{array}{c}\mathrm{S} \\
\mathbf{( \% )}\end{array}$ & $\begin{array}{c}\mathrm{( \% )} \\
\mathbf{( \% )}\end{array}$ \\
\hline $\begin{array}{l}\text { Lawyers can always find an expert who will back up } \\
\text { their client's point of view, no matter what. }\end{array}$ & 16 & 56 & 15 & 10 & 2 \\
$\begin{array}{c}\text { There's a lot of disagreement among experts in } \\
\text { most professions. }\end{array}$ & 12 & 64 & 16 & 8 & 0 \\
\hline
\end{tabular}

Notes: Based on responses of 269 civil jurors. $\mathrm{SA}=$ strongly agree; $\mathrm{A}=$ agree; $\mathrm{N}=$ neither agree nor disagree; $\mathrm{D}=$ disagree; $\mathrm{SD}=$ strongly disagree. 
that jurors are highly gullible and that they overbelieve in experts. Jurors had a similar reaction to the second item, on disagreement among experts. As many as $76 \%$ agreed that "there's a lot of disagreement among experts in most professions." Again this suggests that jurors have a more sanguine view of expertise than perhaps has been appreciated.

Because the items on experts were included in a broader questionnaire, it was possible to determine whether other attitudes or demographic characteristics were related to these views of experts. The strongest relationship was with an attitude scale, the Litigation Crisis Scale, which measured the extent to which a juror believed that there was a litigation crisis and a substantial amount of frivolous litigation (see Hans 2000; Hans and Lofquist 1994). Jurors who showed the greatest suspicion of experts also tended to believe that there were many illegitimate lawsuits. The correlation between the Litigation Crisis Scale and the item "Lawyers can always find an expert who will back up their client's point of view, no matter what it is" was .32, $p<.001$; and the correlation between the Litigation Crisis Scale and the item "There's a lot of disagreement among experts in most professions" was $.21, p<.001$. The correlations are of modest size but statistically significant.

Those jurors who regularly doubt the fairness of the world also seem to be more dubious about the expertise claims of professions. Put another way, jurors who see themselves as efficacious and the world as a basically agreeable place are more likely to grant legitimacy to claims advanced by litigants and, in turn, to be more supportive of expert witnesses.

Logistic regression analyses examined whether there were any links between jurors' demographic characteristics and their general views of experts. We analyzed the potential impact of the jurors' age, gender, education, religion, income, race, marital status, employer type (whether the juror was employed by a major corporation), and union membership. Just one demographic variable, gender, was linked significantly to views of experts. Fully $82 \%$ of men jurors agreed that lawyers can always find a compliant expert, compared to $64 \%$ of women jurors. Another way of expressing the gender difference is in terms of relative odds of agreeing with the statement. The odds that a male juror would agree are 4.62 , while the odds that a female juror would agree are 1.78. In a reduced logistic regression model of lawyers finding experts who would agree as a function of gender, the estimated logistic regression coefficient for gender is $-.940, p<.01(-2 \mathrm{LL}=307.46$, $p<.01)$. Gender was not significantly linked to perceptions of disagreement among experts in the professions, however.

Thus, at least for these general statements about experts testifying in trials, the demographic characteristics of the jurors appear to play only a modest role. These results converge with those of Shuman and his colleagues (1996a) in their survey of Dallas, Texas, civil jurors. Their telephone survey found that no demographic factor was significantly associated with civil jurors' assessments of experts in cases they decided. 


\section{Interview Results}

The questionnaire data provide general information suggesting that jurors are somewhat skeptical of expert witnesses. The more unique analysis we offer, however, lies in our work with the specific comments jurors made about the experts who testified in their trials. In conducting a systematic qualitative analysis of jurors' comments, we took an inductive strategy identified as the "grounded theory" approach (Strauss 1987; Marshall and Rossman 1989). This method is widely used in the social sciences, but to our knowledge has not yet been employed in evaluating jurors' reactions to experts or to other aspects of evidence and trials. We began with all of the jurors' comments about experts, sorted and loosely categorized them, and resorted and recategorized them several times until most of the comments fit in our category scheme. Our aim was to summarize the factors that jurors spontaneously mentioned when they discussed experts and expert testimony.

One advantage of this analytic approach is that the jurors' comments help to determine the nature of the categories. The grounded theory approach thus "grounds" the model and category development in the original words and expressions of the jurors. This may be contrasted to other analytic approaches in which the researcher creates a set of categories and assesses the extent to which the study participants fit those preordained categories.

The current methodology does, however, have some limitations. First, the interviews necessarily took place after the trial, and some psychological research suggests that people may not be fully accurate in describing their decision making after the fact and in identifying the factors that influenced their cognitive processes (Nisbett and Ross 1980). Memory problems can occur, although we attempted to minimize them by providing a list of the witnesses for each case. Another shortcoming is that jurors might have adjusted their responses to present themselves in a socially desirable light or to maximize consistency with the outcome of the trial. These factors should be kept in mind. Even so, the data provide a unique and complementary perspective to prior research on this topic.

In the following discussion, we provide the thrust of jurors' comments about expert witness testimony organized in the form of categories related to either the personal aspects ("the messenger") or the testimony ("the message"). Before embarking on such an analytical journey, we provide the reader with several examples that illustrate the complexity of the jurors' comments.

\section{Jurors' Views of the "Good" Expert and the "Bad" Expert}

We begin our analysis with some illustrations of the ways in which jurors characterized "good" and "bad" expert witnesses. The examples provide some of the flavor of jurors' complex and multifaceted evaluations. 


\section{The "Good Expert"}

Being a "good" expert, the jurors in the cases suggest, does not depend on only one characteristic or feature. As the following examples show, a selected set of characteristics must blend together well:

J: He was an older doctor who [was] well versed. He didn't appear to be somebody who did a lot of testifying in court, and he was a practicing doctor. And he was very good. He explained everything to us in terms that we would understand. I have a back injury myself, and it was kind of interesting. In fact, I said to my wife later, "I wish I had known [him] before. I would've rather had him operate on me than the guy who did it." But [he] was very good. And he was very believable. The jury believed him.

In one of the medical malpractice cases that featured conflicting expert testimony, several jurors explained why they trusted one medical expert more than the other:

J: [she] was a witness for the plaintiff. She seemed to me a very intelligent person. She had backup documents to go along with everything she was saying .... She was the one I felt was the most credible. She was able to field the answers very well from the defendants and to have information to prove that what she was saying was the way it was... . I put more credibility in what she said.

Several jurors in another case evaluated one medical doctor as being extremely good as an expert witness. In fact, one juror said that this expert "was probably the witness that decided the case for the plaintiff." This is how the jurors explained what the characteristics of a "good" expert witness are:

J: [he] was a neurologist. ... He was just excellent and convincing, and he could speak to the court and the jury in lay terms.... He really made things very clear. And I believe he does some teaching, and he was in fact teaching us, showing us, you know, what the systems were, what an X ray looks like in one case and what it looks like in another case. ... And [he] made himself very clear.

J: [he] was very intelligent-if I remember correctly, with a bowtie. That's how I remember. Anyway, he was the one. He showed, he broke things down, he explained to us in detail what the lung was like. I mean he drew pictures; ... they had a little model [of the lung] there with all the parts that fail. . . . He showed us where it was; ... he told us basically that if it was a nodule, if it was a pulmonary blood clot, it would look like this. If it was cancer, it would be shaped differently, and gave us all kinds of different examples of that. Came across as very 
much of a specialist, very intelligent, very believable. And he made it interesting because he explained it so much. He really could explain it well. I guess he's a teacher maybe too.

$\mathrm{J}$ : He was so interesting. He explained everything to us at our level, at a layman's level. We could understand, so it really helped. . . . Yes, everybody understood him. I mean, there was just no question ... he was very, very clear .... . He did demonstrations and brought a model and those kinds of things, so it was very interesting.

In another case-a negligence case involving a job-related injurytwo experts on building and building safety testified. Apparently, one expert made a very strong positive impression on the jurors. Six out of the ten jurors interviewed talked about this expert witness. The common thread through all these comments was that the expert stood up to the attorney on the cross-examination.

$\mathrm{J}$ : He was a very good witness in this case. A very good witness because [the opposing attorney] said, "you mean to tell me that you know every. thing about this book. Every OSHA regulation." "Yes, sir, I do." "Yes, sir, I do." And he [the attorney] could knock every one of the other witnesses down, but this man did not budge.

I: So they were both experts on building and building safety?

J: Yeah. Yeah . . . but the second one was far superb, I mean, you know, he put the lawyers down. I mean he could tell the lawyer where to get off. When he was naturally cross-examined ... this man was able to tell the lawyers, "no offense, mind you, this is my line, so I'll tell you." I mean this guy could just rattle stuff off that was off the top of his head. He could give you facts and figures and run on and on forever, you know, and there was just [no way of] putting him down.

$\mathrm{J}$ : _ was excellent. He knew his stuff. He knew the OSHA standards. He was very good. I think that he's from New York, and he was very, very good because he teaches classes on the OSHA standards.

I: And the OSHA regulations-that man-he pretty much swayed you?

J: Yeah, he did. He did. I like him. He testified really well. He knew his stuff, and he didn't back down from [the attorney], and I liked that. Most people would tend to back down if they're attacked, but he didn't. He knew his stuff and he knew the rules. I just liked that. I thought, he's not lying, and he's not hemming and hawing. He knows his stuff and I liked that. 


\section{The "Bad" Expert}

Like the descriptions of "good" expert witnesses, the accounts of "bad" expert witnesses also included several factors. Here are a few examples:

J: I think that he was the economist from the University __ and he was really deep and really boring, but you could tell from his testimony that he was definitely being paid by the plaintiffs. He was very onesided and you could tell he really didn't get into studying [the case].

$\mathrm{J}$ : He was the thoracic surgeon with whom [the defendant in a medical malpractice suit] worked in hospital, and he was a disaster... for the defense, in my opinion, because he got very flustered and would have to ask for questions to be repeated, which I felt, in many cases, was just a stalling technique because the questions were, you know, kind of turning the screw and putting him very much on the defense in order to answer the question in a way that he didn't perjure himself or incriminate [the defendant] ... he was having a hard time. Very difficult time.

An expert may be labeled as a "bad" witness because of the lawyers too. In one case a juror complained that the lawyers in the case did not explain the connection of the expert's testimony to the case. Several jurors in another case reported that one expert, an economist, whose analysis was supposed to help the jury determine the award, experienced serious problems because the lawyers did not provide all the information to him:

$\mathrm{J}$ : He brought this person in from University __... the best university . . . but evidently, they didn't get the whole story across to what this guy was supposed to represent. . . . The defense just ripped him apart; . . . in fact, the whole jury got a good laugh out of this guy . . . economist, I think it was. And the information they gave him ... he presented the case based on those figures and facts and stuff. Which were wrong. ... They gave him the wrong dates, so all of his figures were off and everything .... it was a joke. Uh, but I felt sorry for [the] economist, because it wasn't really his fault; his figures were so distorted.

\section{A Model of Jurors' Reactions to Experts}

Jurors' comments about experts' credibility can be classified into two major types: comments about personal aspects of the expert and comments 
about the testimony. Regarding personal factors, comments may be categorized as relating to the expert's credentials, motives, or general impressions. As for testimony factors, two broad categories are apparent: those pertaining to the content and those relating to the style of the testimony. A graphic depiction of these categories may be found in figure 1 . Sometimes jurors use one or more of these specific factors to judge an expert, or they may also compare the credibility of one expert with the credibility of another expert in the case.

The jurors' comments reveal that both the messenger and the message are important for a decision about the credibility of an expert witness. Not surprisingly, jurors associate the following with credible testimony: lack of bias; good credentials; a pleasant personality; a clear, objective, focused, not overly long presentation that utilizes diagrams and models; use of lay terms; a presentation that is complete, consistent, and not too complex; knowledgeability in the area of expertise; and familiarity with the case.

Table 2 presents data on comments made about experts organized by categories presented in figure 1 . According to these data, presentation style and its various aspects were the most frequently discussed aspects of credibility $(33.2 \%)$, followed by credentials $(23.1 \%)$ and general impressions about the experts $(20.6 \%)$. These numbers offer only a rough guideline as to frequency of particular types of comments, however, because of the semi-structured interview format (recall that not all questions were asked of all respondents, and, when asked, the wording of the questions occasionally differed). Nonetheless, one may observe from table 2 that the frequency of remarks about these dimensions of experts varies from case to case.

\section{Credentials}

The first interaction a juror witnesses between an expert and an attorney in the courtroom occurs when the attorney establishes the witness's credentials. This was how one juror described the process:

J: Everybody they brought up, they went through their personal backgrounds as far as where they grew up, where they went to school, and service, when they started working at___, and medical doctors went through the same thing, you know. Where they were from, where they practiced at, where they went to school, how well they did in school, and questions like that. They tried making an issue out of B-readers who are people who view $\mathrm{X}$ rays, read from $\mathrm{X}$ rays.

Jurors notice the expert witnesses' credentials and judge accordingly. During the interviews, jurors usually mentioned the specialty or the profession of a particular expert. Most of the time jurors also remembered the name of the institution with which the expert was affiliated. One juror said, 


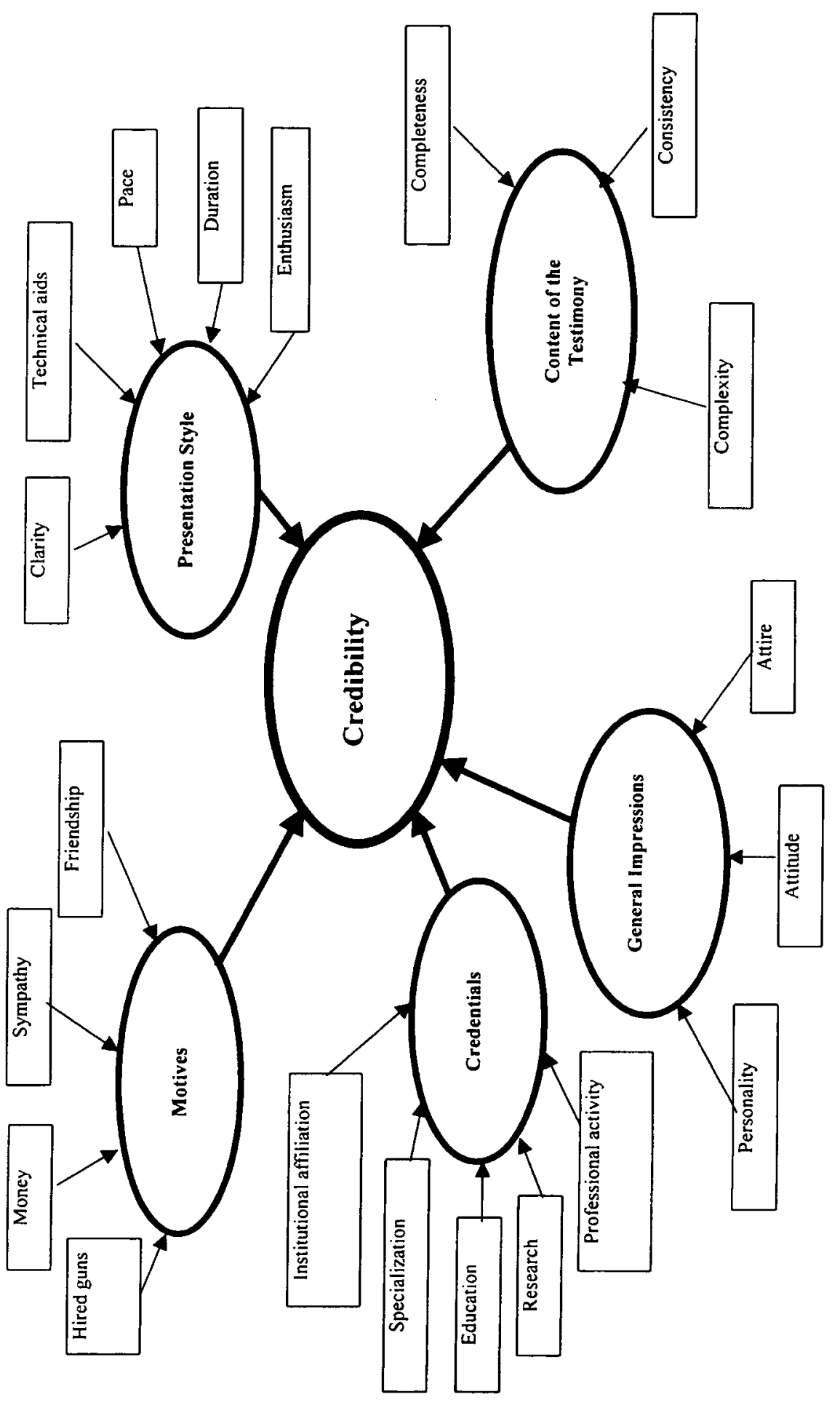

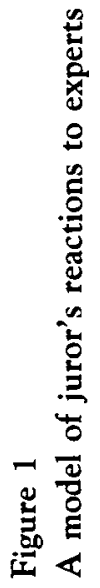




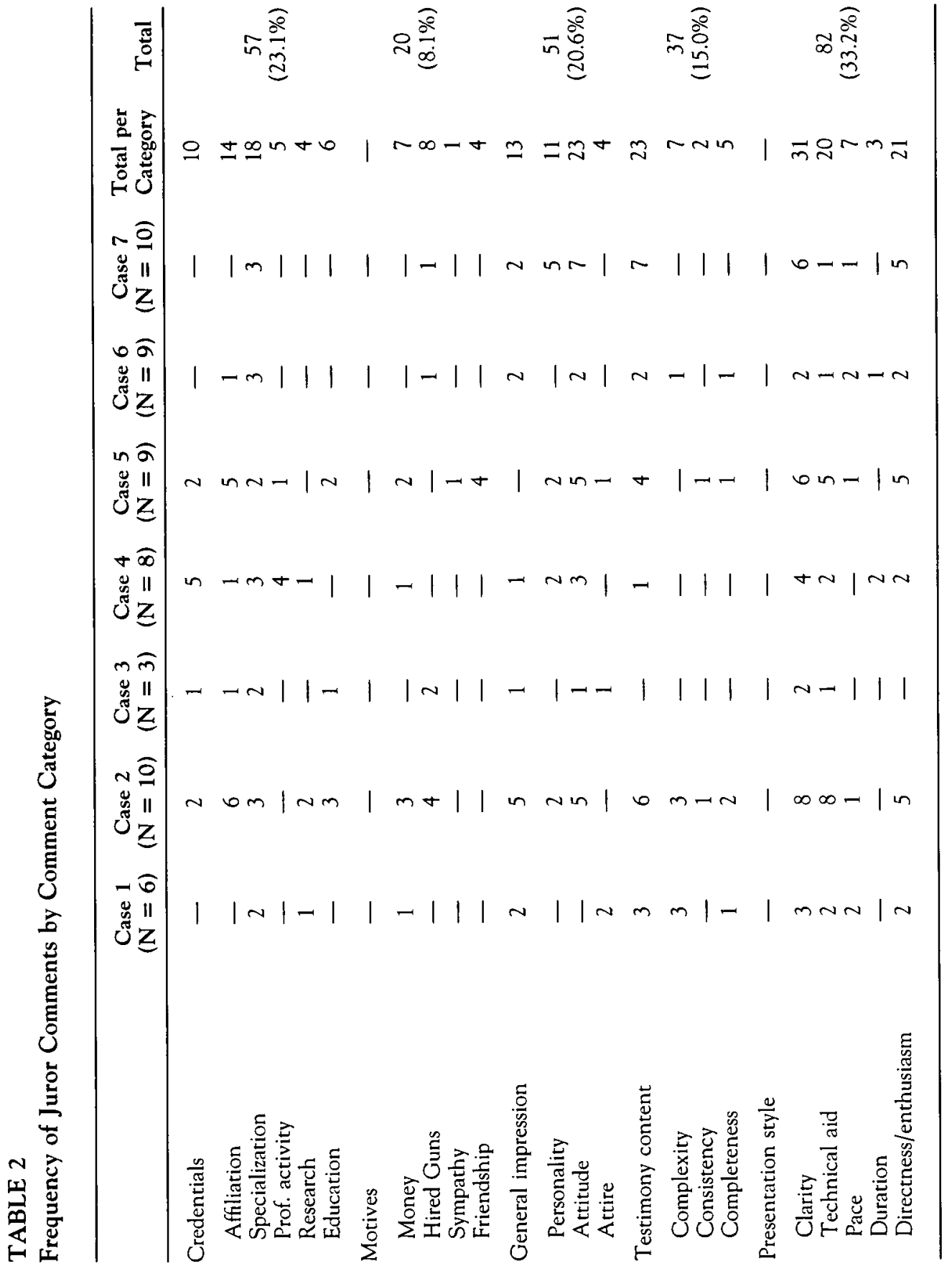


"I had complete confidence in what he said. This may reflect my confidence in the university, I think."

A number of jurors described the expert's professional activity, such as presenting papers at conferences and seminars and research activity. For example, one juror said this about a medical expert testifying in a negligence case: "He's a really old .... He was real influential and [conducted] some of the research that had proven that this stuff [asbestos] was hazardous." Similarly, "he had a lot of credentials; he was very influential as far as that, made [the defendant in the medical malpractice case] look like a little, you know, common surgeon."

Jurors considered formal education in a positive light. This does not necessarily imply that they immediately dismissed an expert witness who lacked formal education. For example, one juror did not seem to mind the lack of the expert's formal education: "He was a biomechanical engineer, but he had no degrees. It was all practical knowledge, which I feel in some ways, I don't have a degree myself, but I thought that was very interesting."

Typically, the jurors who used credentials as a basis for their judgment about credibility thought that experts with good credentials were credible expert witnesses.

J: Some background was given about Dr. and he was on numerous committees. I guess to establish himself as an expert, they presented his involvement in the medical community. He was on some sort of national review board for ___. That's one of the big things he was involved in.

I: Did you find him to be a credible witness?

J: Yes.

I: Was his testimony important? In terms of calling into question what Dr. [the defendant in a medical malpractice suit] had done? $\mathrm{J}$ : Yeah, it was.

Interestingly, having an expert witness with a long list of credentials is not an automatic guarantee of credibility. Credentials were mostly mentioned and used as a factor when jurors compared the credibility of experts from the same profession. When jurors did contrast the credentials of experts, however, they usually found little discrepancy. Typically, their conclusion was that both of the experts were "pretty well respected doctors." Nevertheless, the conclusion was not uniform; some jurors discerned differences in qualifications between two experts. But how did jurors evaluate these credentials? How did they compare one expert witness to the other?

I: What about the medical people that testified for each side? Which did you think was the more effective? The more credible?

J: Dr.

I: Were there obvious differences between him and Dr. 
J: Well, first, the length of the testimony, I guess. With all the things he's been involved in and everything, ... . whereas the other doctor didn't seem to spend all that much time.

I: Dr. __ credentials gave you a more favorable impression?

J: It felt easier for me to make a decision, hearing all his, uh, all his thoughts on the case.

J: He did seminars all over, and he had, really had credentials as far as. . . . Like I say, I don't know how he had time to do all this.

I: Now, did you think he was a pretty credible doctor?

J: Yes, I did. I thought he had good credentials, really.

Most of the times credentials were not the only factors that made a physician stand out. In one case, the credentials, the presentation style, and the content of the testimony all pointed in the same direction, making it easier for the juror to decide. Factors associated both with the messenger and with the message were important:

J: Dr. _ I believe, was a specialist for the plaintiff, and he's [got] quite a background; writing books, and medications, and speaking, and an authority on that problem. I was impressed with him.

I: What was the nature of his testimony?

J: This kind of accident could affect a person's life style. Uh, he spoke with authority; he made a good presence.

I: Do you recall of those two, who at times gave conflicting testimony, which you thought more credible? Which you were more likely to believe?

J: Well, as I said in the beginning, I was impressed with Dr. __, with not necessarily his background - of course, that contributed to it-but of what he said, and how he said it.

Interestingly, one juror in the same case had a positive opinion about the expert when he began to present his credentials, but he changed his overall opinion later:

J: We got really tired of listening to the myriad of publications and where he had spoken, and who he had talked to. We were willing to let it go much earlier than that, but he was qualified. . . . Personalities just have to come through to some extent. And, at first I was sold on Dr. __ but, because he did make a good impression, but then they [the attorneys] went on and on and on [presenting his credentials], I kind of lost faith in him.

Other jurors also were critical and evaluated this expert in a negative way. Some offered two reasons: the expert did not have time to actually practice medicine, and the extensive listing made jurors suspicious: 
J: His credentials were impeccable, but he was on every committee, and I'm thinking to myself, and everybody else in the jury agreed when we were talking about it, if he's so good, why isn't he operating, making money? Why is he on all these committees? This must take too much of his time. If I was a surgeon like he was, I'd be doing the cutting and making the money, not being on all these committees.

J: He seemed like he knew a lot about, you know, his area of expertise. He was a neurologist, a neurosurgeon, but as I said before, the way he was on every committee and his credentials went on for pages and pages and they had an inch-thick thing on him - this is what he's done, you know, he's on every committee, gives speeches all over the place-but to me it hurt because he's everywhere and he's not doing his job.

J: He presented a long list of credentials stating that he was a specialist. When somebody starts doing that, it makes me kind of skeptical. When they start trying to convince us of their honor, we start counting the spoons. . . . He spent, I would say, half of his testimony trying, telling us what made him an expert witness.

I: Do you think his credibility was reduced by the amount of time he spent talking about himself?

J: Well it makes you skeptical. Probably if he had not tried to impress as much ...

I: Do you think the plaintiffs or the defendants had better expert testimony?

J: If you just went by credentials, I would say that the plaintiff had a better expert witness. But credentials are not always, [they don't] always make for the best interpretations. Just like a kid who's going to college when they take the SAT test, and that doesn't always tell the capabilities of the child. They may do lousy on the SAT test, and be an excellent student. So, just because he had a pile of credentials didn't make him good or bad.

It was not always the case that all the factors (e.g., the testimony, credentials) pointed in the same direction. When factors contradicted, the jurors found it more difficult to judge the relative credibility of conflicting experts. For example, one juror preferred the credentials of expert A, but he decided that expert $B$ was more credible because of a better presentation. In another matter, a juror set off the credentials of two conflicting experts against their familiarity with the case:

J: They both had long lists of background degrees and training and experience ... He just didn't have enough of a background in it to really be sitting there, other than to be a character witness, saying "I know this doctor [defendant], he's a good doctor." .. . He hadn't studied it. This other doctor had studied in depth, like I said, I mean he did diagrams, he knew all what happened. 
It seemed that jurors experienced a greater challenge when they had to evaluate the credibility of two conflicting experts with different specializations, as illustrated in this comment: "Dr. ___ is an orthopedic doctor. Dr. _ is a medical doctor. So, it's two different things. So there's two different doctors; you really can't compare them too much I don't think."

In summary, jurors definitely used credentials to evaluate the credibility of an expert witness. They discussed institutional affiliation, specialization, education, research, and professional activity. Although a long list of credentials was generally perceived in a positive light, it backfired in at least one instance, reminiscent of Cooper and Neuhaus's mock jury findings (2000). Credentials were also used to evaluate credibility in combination with other categories, such as familiarity with the case or presentation style.

\section{Motives}

Jurors tried to reason about the motives that brought each expert to the witness stand, although the interviewers did not explicitly ask about the motives. Still, in discussing motives, they rarely mentioned motives that would enhance one expert's credibility in comparison with another's. Instead, they focused primarily on characteristics that reduced an expert's credibility.

For example, jurors carefully examined and weighed potential motives for bias. As indicated in figure 1, typical motives were monetary gain, friendship with the attorney or one of the parties, and primarily in medical malpractice cases, sympathy with the defendant. The majority of the comments dealing with motives focused on monetary gain and the effect of payment on objectivity or bias (see table 2 ).

Jurors observed that the attorneys tried to discredit the expert of the opposite party by asking him about the expert's fee. They noted and commented about the (high) fees paid to the expert witnesses:

J: I was very interested also in their fees, which were-it was funnythey were getting like four hundred dollars an hour. Well not all of them, but one was getting, two or three were getting four hundred dollars an hour; one was getting two hundred and sixty-five dollars an hour; and we're saying, you know, "We're getting fifteen dollars a day." I: Was that true for the doctors on both sides?

$\mathrm{J}$ : Yes, yes.

Emphasizing the large fee paid to the experts may not be a winning tactic all the time; in fact, it may backfire. For example, in one case, the attorney for the defendant tried to argue that the expert testified just to secure several thousand dollars worth of medical treatment in the future. What did one of the jurors conclude? "No, he pursued that so much, he 
tried to discredit him [the expert] so much in that way and everything else and [it] made [the attorney] look cheap."

Being paid more did not necessarily discredit one expert over the other, a result that again reminds us of the Cooper and Neuhaus mock juror results (2000). In our research, in a case of medical malpractice, the defendant invited one of his colleagues from the hospital to provide testimony. From evidence presented in the courtroom, the jurors learned that this expert was charging only a quarter of his usual fee, so they declared him less credible than the experts for the plaintiff, who charged more. The perception was that the defendant's colleague was biased; he was testifying for his friend. Here the fee interacted with a second motive-friendship.

One juror expressed an overall objection to the fact that expert witnesses were paid. This juror was concerned about "hired gun" expert witnesses:

J: It's that somebody will do it for money. And I think that was the largest, in my impression, the largest motive pushing the expert witnesses, is money. And that sort of discredited the witnesses, the expert witnesses toward, for me, well, you know, both sides. . . . But I did take, I took that into account. Also, I looked at their evidence that they presented, which, a lot of it I found interesting and informative.

Similarly, several other jurors shared this general concern about the objectivity of the expert witnesses' testimony because they were paid. For example, one juror contrasted two experts and made a decision based on their motives:

J: Dr. seemed like a competent individual, not really trying to, even though he was a witness for the plaintiff, didn't seem to try to sway one way or the other, was just trying to state the facts, I guess, as they were. And was somewhat informative as far as the specific nature of her [plaintiff's] follow-up surgery, and what those complications or problems were. Dr. __ [the other witness] seemed to be more for the plaintiff as far as her cause and things like that and answers seemed to be skewed in that way accordingly.

Another juror compared the credibility of expert witnesses to that of other (unpaid) witnesses. The paid expert did not fare well, largely because of the financial incentive:

J: [Those two witnesses seemed credible] because they were not expert witnesses, they weren't being paid for their time. They were volunteering their time and their eyewitness account of what happened. They're not going by what the lawyer told them, what they signed, or instant replay. 
However, not all jurors associated payment with less credibility.

$\mathrm{J}$ : The defense only pointed out that these expert witnesses were being paid for their appearances.

I: And did that influence their credibility?

J: No, I expected them to be awarded for it, the time that they'd spent in this, researching it and exploring it.

Another juror shared this opinion, but was cautious about the expert witness who testified frequently:

J: One of the doctors, I remember, was from and had been there for years and was now doing more in consulting type work, and I just remember, I felt like I was sitting and watching the movie The Verdict. I mean, because it was a doctor who was semi-retired and ended up testifying in like 75 cases in the past two years or something like that. . . I mean I didn't see any question or problem with physicians testifying. I don't see a problem with charging ... for his time to come in because he'd be charging patients, and so that's what he would charge anyway, so I found it credible and I didn't have a problem with all the other questions.

In another case, the attorney mentioned that the expert witness for the opposite party had testified in a number of similar cases. Jurors discredited experts who appeared in a number of similar cases with the same attorney: "The defense attorney brought out that $95 \%$ of this guy's income is just testifying in asbestos cases all over the United States, and then you felt like he had a racket." Jurors interpreted that information as a reason that undermined their credibility ("I guess the guy makes spare pocket change by doing extra witnessing").

Clearly, motives were an important category, and they were mentioned by at least one juror in each case in the sample. For example, even when most jurors liked a medical doctor's testimony and described her as a very good expert witness, her involvement in previous cases became a problem in the eyes of some jurors: "She was strictly a plaintiff's doctor":

J: Dr. — , boy, we were waiting for her to come, because we kept hearing about her, all before she came, so the big day she came, she was on that stand all day long. ... We really felt like she was really into her work and stuff until she came out and said, "Well, yes, I've examined 300 of [the attorney's] clients" ... . And you're thinking, "Well, gosh, does she have a racket going?". . . She was pretty interesting and stuff. She seemed pretty straightforward and would go through the $\mathrm{X}$ rays and her findings and stuff, but, I don't know, you just felt like she maybe was having a racket with this attorney. I mean, I felt 
like she was a good doctor and knew what she was doing, but, yeah, she kind of had a racket going.

The second case in which jurors compared two categories-motives and testimony - was the asbestos case. After discussing the content of the testimony, a juror concluded that, although one expert had delivered agood presentation, and was generally liked by the jury, he was discredited because he had been an expert witness in a number of other cases handled by the same attorney. A juror in another case was faced with a similar situation: He needed to evaluate the testimony given by an expert who had testified quite frequently in medical malpractice suits. His evaluation was quite different:

I: Did you have any questions about his credibility, given that he testified quite frequently and was being paid a lot of money?

$\mathrm{J}$ : Not really because he had good credentials, and I didn't question his credibility.

The majority of the jurors who commented on monetary motives attributed a negative connotation to them and questioned the potential objectivity of the expert witnesses. This was a typical comment: "He was definitely being paid by the plaintiffs. He was very one-sided and ... he was there testifying for the plaintiff."

In a medical malpractice case, the defendant invited an expert witness to testify, and jurors heard during the trial that this expert witness had been involved in a medical malpractice case himself. We might expect that the jurors would be skeptical of his testimony, but interestingly, not all jurors were:

J: It was mentioned that his [defendant's] expert witness also had been involved in a malpractice case at one time.

I: Did that diminish his credibility?

J: No. I don't think it did.

Friendship was another potential source of motivation to provide expert testimony. As noted above, one expert witness in a medical malpractice case was a colleague of the defendant. Jurors noticed that both of them had worked in the same hospital, and they attached different consequences to it. The majority of jurors discredited the expert, stating that he was a friend of the defendant. One juror was asked how he would evaluate the credibility of the expert if the expert were an outsider who said the same thing. The juror confirmed that he would judge it differently, supporting the general opinion that being a friend with one of the parties or attorneys in the case limited the credibility of an expert witness. 
I: Was the credibility of Dr. 's testimony diminished by the fact that he was a colleague of Dr. [the defendant in a medical malpractice suit]?

J: I believe so.

I: If he had been an outsider who had said that, you might have found it more credible?

J: Yes. I thought that he was biased in that opinion. And that it was also brought out that he treated or thought of Dr. [the defendant]

like a son. And that was mentioned on more than one occasion, and it wasn't denied either, or refuted.

J: I only remember one guy who made some testimony. He was very much a good friend of Dr. [the defendant in a medical malpractice suit] and, I think, was testifying on his behalf. And the only part of his testimony, I guess his whole testimony, was brought into question when the plaintiff's attorney made some points to the fact that Dr. ___ had agreed to testify before seeing all the components of the case.

I: Which led you to think ...

J: That he agreed to testify on someone's behalf without knowing why it was he was testifying, or whether he was actually in fact testifying for somebody that he should have been out there supporting from a medical standpoint.

I: So this is more, perhaps, more out of friendship than out of medical agreement?

J: Yeah, right, exactly.

I: So did that lessen the importance of what he was saying?

$\mathrm{J}$ : Oh certainly, certainly, certainly it did.

In sum, it seems that jurors' thoughts about or discussions of the experts' motives usually had a negative impact on credibility. Motives discussed by jurors can be classified as monetary gain, hired guns, sympathy toward the defendant, and friendship with the defendant. If jurors raised the issue of an expert's motives, they typically found a serious concern that impacted on the expert's credibility.

\section{General Impressions of Expert Witnesses}

Jurors made a number of highly detailed comments about expert witnesses that were outside the categories of credibility, credentials, and motive. We call this category "general impressions of expert witnesses," and it includes comments about age ("He was an older doctor"), race ("He was a black physician"), gender ("the lady doctor"), nationality ("I believe he was the Irishman"), physical appearance ("He's a tall man with blonde hair, wasn't he?"), and dress of expert witnesses ("One of them wore bowties. Which one was that?"). Either these factors did not influence jurors' judg- 
ment about credibility, or they did not want to tell the interviewer that they made a difference.

Other factors in this general category include the expert's personality and attitude, as well as any personal acquaintance with the expert, and jurors' judgments about these factors did appear to influence their assessment of expert credibility. Manner of speech, an element that also can be categorized as "presentation style," was important ("he was very well-versed"). As one juror said, "We all got a big kick out of him because he was neat to listen to." Most jurors who emphasized the personality of the expert (such as intelligence, sense of humor) found that credibility was in fact aided by personal factors. Even a juror who found an expert arrogant displayed no overall negative impression ("even though he came off as being a little bit arrogant, he was believable"). Some jurors used the term attitude to identify the expert's personal style or personality. One juror linked the expert's personality and attitude, saying: "I didn't care for this Dr. I didn't care for his personality, his attitude . . . but that didn't sway me one way or the other."

A juror's personal acquaintance with an expert, or some knowledge about the expert that was not obtained during the trial, such as general reputation of the expert, could influence the assessment of credibility in either a positive or negative light. For example, in one case, an expert's credibility was bolstered by the fact that the expert was a doctor who had treated one juror's mother. However, another juror in the same case perceived the media publicity of a prior sexual harassment case filed against the expert as a negative factor in assessing the expert's credibility.

In summary, jurors discussed general impressions of the experts, but they related only some of these impressions to credibility (e.g., those involving the personality of the expert and his or her attitude), while some others (e.g., gender or dress of the expert) were not related to their evaluations of credibility in an explicit way.

\section{Testimony Factors}

Testimony factors, or evaluations about the "message," may be divided into those involving the presentation style and those involving the content of the expert witness testimony. As reported below, both were crucial in evaluations of expert witness credibility.

\section{Presentation Style}

Jurors not only judged experts as individuals; they also attended to their presentation of technical material during testimony. Consistent with research such as that of Jacoubovitch et al. (1977), which showed a preference 
for direct testimony over mediated testimony, jurors far preferred live testimony by experts over the reading of depositions: "The depositions were sometimes hard to follow. I don't know if that was just loss of attention when they were reading 176 pages." They were particularly negative about generic depositions: "I felt like they went to him just for this specific case. I would have listened to it more, but I just felt like this was just a run-ofthe-mill one."

Jurors' assessments appeared to be influenced by how experts presented their information. Clarity of presentation was critically important. Most of the jurors emphasized it, viewing it as an important part of the expert's credibility. It seems that the best expert witness comes across as a very good teacher-someone who knows how to make a presentation:

J: Dr. _ was incredibly interesting. I mean, if you can get an education, this man was wonderful. He explained things to you; you understood what he was talking about. He was very clear, as a matter of fact, when he would get up and demonstrate something. . . . He was very, very good, he knew exactly, he seemed to know exactly what he was talking about. He was very believable.

$\mathrm{J}$ : He was extremely knowledgeable. .. . The way he explained things to the jury and to the courtroom, we all understand perfectly. He would have been a great teacher. He explained everything great. He was the best witness they had. They couldn't have [done] better.

Jurors felt more comfortable and regarded experts as good when they adjusted their vocabulary for a lay audience during the presentation. Jurors appreciated explanations given in less technical terms: "He explained everything to us, in terms we would understand."

Furthermore, they did not have a lot of mercy for experts whose focus of testimony was boring or unclear: "There were times when the testimony was very dull and technical, and you might have a tendency to, your mind would wander. You'd have a tendency to want to doze off."

Jurors appreciated the use of some forms of technical aid as part of the expert's presentation, whether it was a model, chart, diagram, or X ray.

J: Dr. was here from [local town], and he was very good. His point was well taken. He had a lot of details, a lot of $\mathrm{X}$ rays to show, to help you understand why he had made the decisions that he had made.

J: And they went through, made diagrams on the chalkboard, the internal structures in the woman, you know, and what was done, exactly what was done and things like that. So, I don't think that it was very, that hard to understand. 
Similarly, for testimony where the presentation pace was tedious ("he was going date after date after date"), or when the presentation was too long for the jurors, the jurors found it to be challenging: "Dr. _ , he went on and on and on. He was there for I bet an hour, at least. Some of them kind of get sing-song. Of course, it was long, just sitting, sitting." In addition to good pacing and brevity, jurors valued directness and enthusiasm. An expert witness who did not hesitate to answer the questions, who "didn't beat around the bush," was liked better. In the asbestos case, one plaintiff was apparently on the borderline of asbestosis, and some experts said that he had asbestosis, while other experts disagreed. One juror particularly liked the expert who just said that the defendant was a borderline case. The juror interpreted the expert's statement as objective, and regarded that expert as credible: "He was extremely good, believable, particularly in the one instance somebody was a borderline, and he just said, he said, 'It's a borderline." "

By contrast, evasive expert witnesses were not appreciated:

J: He seemed real evasive sometimes. Like when the attorney would ask him certain questions, he would like try to get around it, start giving you big explanations for something you didn't even want to know. That's all I really got to say about him. He wasn't too believable at all.

Jurors saw experts with a range of specialties and skills at presenting substantive issues. The quality of presentation appeared to affect the jurors' ability to understand the issues:

I: Did you find any of the evidence difficult to understand?

J: In this particular case?

I: Yes, in this case.

J: Yes, some. It depended on the witness. Now, some of the witnesses were, they hit the whole spectrum. They went from earth-type person all the way up the scale to biochem, uh bio, what's the term they used? I know it's his title. It's biomechanical engineer. And this particular guy, that's what he lived on, data. Everything was data, pretty much. He was trying to make graphs out of data.

Occasionally, jurors compared two factors or categories. For some experts, a good presentation style was compared to some other factors, such as motives. In one medical malpractice case, a medical expert described the procedure that the defendant should have followed, and he presented facts clearly and objectively, according to the jurors. They liked his presentation style so much that they did not consider him biased when he became emotional about what had happened to the plaintiff as a result of medical malpractice. 
J: He was very believable. I mean, to the extent that at one point he almost became emotional about what had happened. It was like, "How could you do this? How could you damage this man's life?" You know. And you believed that that's exactly what he believed happened. That this Dr. — [the defendant] just did not care. He went in and did it, and he just did it.

J: Dr. was probably the witness that decided the case for the plaintiff. ... . He was a very good witness. He spent a lot of time discussing embolisms and infarcts, and actually he became quite emotional when certain questions were asked. You could tell that his sincere opinion was that this procedure was totally unnecessary and that it was malpractice on Dr. __ [the defendant's] part not to have picked up on the fact that it was an embolism.

Thus, jurors noticed the way the testimony was given and the facts presented, and they preferred clear presentation in lay terms, paced well, not too long, given enthusiastically, and supported with technical aids. As the malpractice case just cited suggests, a good quality presentation may help to counteract problematic motives.

\section{Content of Testimony}

Although jurors are frequently accused of being unable to understand the content of testimony and consequently resorting to more subjective factors when judging an expert's credibility, jurors in this study often remarked about the content of the testimony. Some gave short summaries of what the expert had said; others discussed the details of the testimony. In a worker injury case in which a scaffold had collapsed, the expert testified about the building of the scaffold and safety procedures. One juror summarized his statement using the following words:

$\mathrm{J}$ : He just sat there with a monotone voice and just told us exactly what pump jack scaffolding was. Exactly how it was to be used. Exactly what kind of wood it was supposed to be used with. How many nails were supposed to be in each board. How far apart the nails were supposed to be in each board. How you were supposed to check and make sure that the board had nothing wrong with it.

Similarly, a juror in a negligence case discussed the content of the expert testimony:

J: He gave us all the figures on how long this young man's going to live, what it's gonna cost to take care of him, what his medical bills have been. He explained how, if we were to find in this boy's favor, how we're to determine exactly, how to convert tomorrow's dollars to today's dollars, and things like that. 
I: Did you find that helpful, when the time came?

J: Yes, yes.

I: So, he generally was a credible witness?

$\mathrm{J}$ : Yes he was.

The majority of the jurors tried to critically evaluate content. One factor they considered was consistency: "Both of the doctors for the defense, they were completely unbelievable. Their testimony differed so much from their deposition. They took like half a day each, almost a day at a time, for each of them, because there were so many differences in the thing; they kept bringing that up." This shows that the common litigator tactic of pointing to differences between deposition and trial testimony can be effective in decreasing credibility.

Jurors also looked for points of the testimony that seemed illogical or wrong, based on their own knowledge. In one case, where an economist was called to suggest how to calculate the award, jurors used their experience to evaluate the testimony. The expert made rather generous assumptions about the pension the plaintiff would have earned if he were healthy and could work until old age, but it contradicted jurors' personal knowledge of pensions in the state.

J: It just doesn't make any sense, of what the people were earning, and what they could earn and so forth. Hell, I knew what people earn at _ [the organization where the plaintiff worked]. I knew what all their pensions were. The numbers they were putting up there were ridiculous.

The jurors thus compared their collective fund of information with the expert's testimony. When they found a discrepancy, the jurors used expert testimony as a jumping-off point, adjusting the figures as they thought appropriate.

Completeness of testimony was important to jurors also. They viewed experts who explained everything that appeared to be important to the case as believable. Conversely, experts who omitted some significant parts of the explanation were perceived as less credible.

The complexity of the testimony and the jurors' ability to understand it also played a significant role in how jurors responded to experts. Not surprisingly, jurors reported more problems with testimony that was technically complex: "They got quite technical in a lot of the medical instances, and so, overall, just generally speaking, I could understand what they were saying. Still, a lot of the technical got pretty, got pretty deeply in."

In one case, an economist testified about the award, and one juror commented, "I understood what he was trying to do, but as far as him arriving at the figures and all, I didn't comprehend." In general terms, then, use of 
the expert witnesses involves an essential paradox: Jurors, who are lay people, need to understand and evaluate unfamiliar issues. Several jurors recognized the problem:

J: There was an awful lot that I couldn't understand because, well that's true with everything. You know, if you're not a major in music-if you don't major in music and you major in some other subject - and somebody gets up and starts telling you all of these technical things about the $G$ clef and the half notes and tone qualities and all that sort of thing, it's not going to mean very much to you and you're not going to understand much of what's they're saying. And that's just the same way with these categories. These men were experts in the field of pressure.

I: His testimony was hard for you to understand?

J: Basically because of the fact that I know nothing about construction. I know nothing about medical terms or legal terms, which the doctors talked medical stuff that I didn't understand. The lawyers with their long words for short definitions.

J: We were a cross-section of the lay public, and we didn't know that much about asbestos and asbestosis, prior to the trial, and I believe everybody was educated to a great degree by the presentations of the experts that the plaintiffs and the defense brought in.

$\mathrm{J}$ : And it was so dry, you know, and so cut and dry, and naturally I didn't understand what scientific reasons why, what force and velocity ... that would cause, and all these things. This is what they talked about a lot. All these kinds of things.

The interviewers routinely asked jurors, "Was there any evidence that was difficult for the jury to understand?" In response, jurors reported that the way in which complex testimony was presented affected whether they had trouble comprehending the evidence.

J: I think had it not been explained as well as it was, yeah, perhaps it would have been, you know ... there are certain things that I wouldn't have understood. There were medical terms used that I would not have understood. However, they were explained in detail.

J: No. When they explained it, they explained it in language that we understood, and they used diagrams and pictures. They were very simple to understand.

J: They were a good reference, because there was so much written and verbal argument, and times, and circumstances, places, impacts, and feelings - a lot of technical data. I mean, you had to be an engineer to understand a lot of this stuff. And they try to make it as plain and as clear as they could for us. 
Clarity and repetition, as the following juror emphasized, played a crucial role: "they explained it-they went over it often enough that they explained it really well-so I didn't find anything really too difficult to understand." When asked whether any medical testimony was difficult to understand, the same juror answered: "No, they explained it pretty well." Similar comments were made by a number of other jurors.

$\mathrm{J}$ : He seemed to be a very competent doctor. His testimony was on videotape, and I was impressed with the way he matter of factly presented the extent of damage and explained in layman's terms what the damage was.

I: So he made the medical testimony understandable.

J: Yes, he did.

If the experts used complicated professional jargon, lay jurors had a more challenging task.

I: Was any of the evidence either for the plaintiff or the defense hard to understand?

J: Well, they would bring up pleural plaques, and then they had another phrase that meant the same thing, and they were using that intermittently, and until we got that straightened out, it was a little bit hard to understand.

I: So you, I guess, had a hard time, then, reading the $\mathrm{X}$ rays and interpreting them independently?

J: Yeah, and a lot of the medical talk. . . . It was like, speak English. Put it in layman's terms.

J: It seemed to me that they made the effort, knowing that we weren't of the medical background, to explain terminology whenever it seemed to be a foreign language.

I: And you felt pretty comfortable with the medical evidence?

J: Yes.

Furthermore, when used, various technical aids generally improved the clarity of the experts' presentations and helped jurors better understand the subject matter. For example, some experts used pictures, charts, diagrams, $\mathrm{X}$ rays, or models. When asked whether the medical evidence was difficult to understand, one juror remarked, "A lot of it was medical terms, and they had a chart showing how the bones worked, what causes backlash [witness speaks of whiplash] when you go forward and back. That was helpful. Mostly we could understand it."

Sometimes, to clearly present the major points of the testimony, experts needed to cut out the details. Jurors preferred clear explanations of important points over detailed explanations. One juror said, "I could basically 
handle most of it. A lot of it you had to weed out the details to get to the level of information that you needed to know."

Overall, then, jurors' comments show that a good, clear presentation can make complex testimony more understandable, as can terminology that is appropriate for a lay audience. The ability of experts to "speak English" and translate technical concepts into lay terms makes complex testimony more useful during the deliberation.

Although jurors did not usually have substantive knowledge of the expert's subject (which is, of course, the formal reason for inviting an expert to testify), most of them developed some impression about the knowledge of the field displayed by the expert and commented on it-for example, "He knew a lot about his area of expertise," or "I thought he knew what he was talking about," or "I thought he was a good surgeon. He evidently was a good surgeon. He knew what he was doing. I got that impression." One juror made the following point, however: "It seemed to me that he knew what he was talking. If he didn't know what he was talking about, you know, I couldn't have told, have been able to tell."

Some jurors were in a better position to understand testimony than the others, because they were at least partially familiar with the subject matter. Those jurors reportedly turned out to be very important during the deliberations. In the case with the collapsing scaffold, jurors had problems understanding complex issues of building and safety. One juror emphasized the importance of being familiar with the subject: "There were some guys [other jurors] that knew about construction, and they would try to make it clear for the rest of us exactly how it looked."

We've already seen that jurors attempt to deal with opposing experts by comparing their credentials. Similarly, they tried to resolve conflicting expert testimony by contrasting motives and the substantive aspects of the testimony. Jurors might also compare an expert's conclusions to some other evidence in the case, such as medical tests, $X$ rays, or the testimony of a lay witness. For example, in the asbestos case, expert testimony about the correct results of medical tests was contradictory. Thus, jurors averaged the scores of both tests and found an effective, if not accurate, way of circumventing the problem of conflicting testimony.

J: We would write - that's when we made our charts, you know-we'd write it down and we'd compare. But they all did the same tests. And we'd just compare what levels these people had and come to an average. I: Of all the doctors?

J: Yeah ...

I: Okay, so, you kind of averaged their scores, his scores together, to get something?

$\mathrm{J}$ : Yeah, yeah. 
Several jurors explained the other methods they used to decide whom to believe in a case of conflicting expert witnesses. Some said that they relied on their intelligence, watched body language, and/or tried to use other psychological tricks:

I: How did you deal with that conflict?

J: Where I could, I used experience and knowledge that I had. Where I couldn't, which was more the case than otherwise, I went on the level of detail that the person had, the train of thought the person carried, the confidence with which the person gave their answers, the willingness to field any defending questions without belligerence, you know, with a degree of confidence, saying, "I know what I'm talking about." And, that's basically how I did it. I didn't know any other way.

J: Just being relatively intelligent you can tell who's trying to sway you, or who's trying to sell you their own idea versus what's the truth.

I: How'd you try to figure out, when you had the two doctors that disputed each other, which one was right?

J: You can tell when they lie.

I: You can tell? How do you tell?

J: I don't know. If you look at people and study people, there's something you can find out, you know, from the get-go about them. . . . People will pay you and sway you to do things.

I: Do you think that was happening in this case?

J: Yes.

I: Do you look for anything in the way they speak, or is it more what they say?

J: You look for the way they speak. You look for the eyes. You look for the movements. You look to see how much nerve. If they go like this, or rock like this, the witness. If he rocks like this and the other lawyer asks him a question, and he'll make like he don't understand the question. Then they're wishy-washy.

In summary, when jurors examined the content of testimony, they considered its completeness, consistency, and complexity. To better understand the complex expert witness testimony and soften the "essential paradox" of the expert testimony, they relied on presentation style. Thus, jurors discussed the relationship between presentation style (or its elements, such as clarity or use of technical aids) and the understandability of evidence, and they emphasized that everything else being equal, the clearer the presentation, the better they understood the evidence.

\section{CONCLUSION}

Expert testimony plays an important role in civil litigation; in many cases, it is the dominant component. Unlike jurors in a typical criminal 
case, jurors sitting in a civil case frequently encounter not only one but several-usually conflicting-presentations of expert testimony (Gross 1991; Krafka et al. 2002). Thus, they face a paradox: Jurors routinely need to evaluate expert evidence in order to make their decisions, yet their expertise with respect to the evidence is usually limited. Our research addresses the question of how jurors approach the challenge of this essential paradox of expert testimony.

To date, relevant answers to this question have been limited. Reliable data on how expert evidence is received and used are scarce. Although expert testimony is the subject of extensive attention from scholars, judges, and lawyers, existing research on jurors and experts has mostly focused on determining comprehension problems. Mock juror and jury studies, limited in their implications by their methodology, have inquired about the ways jurors react to specific types of expert evidence, such as statistical evidence, battered women syndrome evidence, or eyewitness-identification evidence. By contrast, there has been relatively little research examining jurors' reactions to two of the most frequent types of expert evidence-medical and economic expert evidence.

The research reported in this article examined actual jurors' reactions to expert witnesses by providing jurors with an opportunity to describe their experiences in a semi-structured interview setting. We analyzed transcripts of interviews with jurors in a variety of civil cases (ranging from workplaceinjury cases to medical-malpractice cases) involving a number of expert witnesses in each case. Although this method is not without its inherent methodological challenges, as described earlier, the data provide a unique and complementary perspective to prior research. By systematically studying the factors the jurors reported focusing on while assessing expert evidence, we have developed a fuller and more detailed model of expert witness credibility.

The questionnaire results showed that most jurors expressed some reservations about the experts at the outset, rather than accepting expert assertions uncritically, as is often supposed. The American legal system, adversarial in nature, rests on the assumption that the decision maker has a passive role and the parties build their cases (and, consequently, hire experts to support their arguments). Although the nuances may escape them, jurors seem cognizant of the broad adversarial pressures on experts. They expressed worry or disdain for those experts who testified frequently, especially once the opposing attorney raised questions about frequency and the amounts of money received by the expert as compensation.

Vidmar's (1995) work on juries in medical malpractice cases also reached the conclusion that juries consider the adversarial context in assessing expert credibility. The disapproval that jurors in our study expressed about expert witnesses perceived to be hired guns, or about experts who were close friends with the defendants in medical malpractice cases, is also consistent with other research (e.g., American Bar Association Special 
Committee of Jury Comprehension 1989; Sanders 1993; Cooper and Neuhaus 2000). By acknowledging the adversarial context and the potential motives of expert witnesses, jurors reflect a more sophisticated and less naïve view of legally provided expertise than might have formerly been appreciated. Interestingly, jurors show some of the same predilection to question expert motivation as the Supreme Court justices do in Kumho Tire (1999). Sanders, Diamond, and Vidmar (2002) argue that opinions in the Kumho Tire case reflect a judicial concern for adversarial pressures that may affect the content and credibility of expert testimony.

In several other ways, our findings converge with empirical research conducted using divergent methodological approaches. For example, the findings on importance of clarity and accessibility of testimony for a lay audience confirm the results of earlier studies on juries and experts (American Bar Association Special Committee of Jury Comprehension 1989; Sanders 1993; Champagne et al. 1992; Shuman et al. 1994) as well as the broad conclusions of research on jury comprehension of legal instructions (Tiersma 1999).

In surveys by Shuman and his colleagues (see, for example, Shuman et al. 1994, 1996a, 1996b), some participants believed that jurors focus mainly on the personal characteristics of the expert. We found, however, that making a decision about the expert's credibility, jurors examined both personal characteristics of the messenger (credentials, motives, and general impressions) and dimensions of the message (presentation style and content).

That said, the factors jurors identified as most important were not identical for each case, each expert witness, or each juror. It would have been interesting to explore whether the complexity of the evidence affected the factors that jurors mentioned most frequently. Such research could use real jurors to test the Cooper et al. (1996) proposal that jurors confronted with difficult testimony shift from central processing to peripheral processing and rely more heavily on shortcuts such as credentials. We had insufficient numbers of cases to examine this hypothesis.

Of interest to scholars and practitioners alike, jurors clearly agreed about the characteristics that led them to evaluate an expert as highly credible. Such experts were generally described as good teachers with sound credentials and acceptable motives. Further, the juror model of expert credibility that we developed using a grounded theory approach overlaps substantially with the factors that judges and lawyers identify as characteristic of good experts (Chesler, Sanders, and Kalmuss 1988). In interviews with lawyers and social scientists in desegregation cases, Chesler et al. (1988) asked what factors made expert witnesses more credible. In a notable convergence with our juror data, the majority focused on the skills and tactics of presentation and style. Significant minorities of lawyers and scientists emphasized technical knowledge or expertise such as good credentials, good 
data, or good experience, and knowledge of the local area. Indeed, in assessing credibility, although the frequencies differed to a degree, both lawyers and scientists most often mentioned the experts' ability to communicate clearly and specifically, to maintain integrity and neutrality, and to avoid being adversarial. Considering our juror data and the Chesler et al. (1988) results together, we are struck by the similarities between the juror model of expert credibility and the model of expert credibility held by legal and scientific experts.

In closing, we note that from the point of view of the lawyers, expert witnessing may be characterized as a "performance." Lawyers commission and direct these presentations. The determinants of the performance begin with the lawyer's choice of a performer (casting) and proceed to the content of the testimony (script) and the manner of presentation (staging). If these efforts are successful, the audience's perceptions of the messenger and the message unite to form their reaction to a performance that is designed to have a specific impact-like the intertwining of character and plot in a play. As we learn more about how jurors respond to experts, it is worthwhile to keep in mind that the dimensions of expert performance are chosen and created with the aim of influencing jury decision making. Arguably, one important function of adversarial cross-examination is to help jurors pull back the curtain on the performance of an expert witness. Research that examines the relative effects of credentials, motives, presentation style, and content on expert credibility may show more fully how jurors judge the expert performance presented to them.

\section{REFERENCES}

American Bar Association Special Committee of Jury Comprehension, Litigation Section. 1989. Jury Comprehension in Complex Cases. Chicago: American Bar Association.

Brekke, Nancy, and Eugene Borgida. 1988. Expert Psychological Testimony in Rape Trials: A Social-Cognitive Analysis. Joumal of Personality and Social Psychology 55:37286.

Brief Amici Curiae of Neil Vidmar et al. in Support of Respondents. 1998. Kumho Tire v. Carmichael, 1997 U.S. Briefs 1709.

Casper, Jonathan D., and Shari Seidman Diamond. 1993. Estimating Damages and Predicting Violence: The Influence of Experts in the Courtroom. Paper presented at the meeting of the Law and Society Association, Chicago, May 1993.

Cecil, Joe S., Valerie P. Hans, and Elizabeth C. Wiggins. 1991. Citizen Comprehension of Difficult Issues: Lessons From Civil Jury Trials. American University Law Review. 40:727-74.

Champagne, Anthony, Daniel W. Shuman, and Elizabeth Whitaker. 1992. Expert Witness in the Courts: An Empirical Examination. Judicature 76 (June-July):5-10.

Chesler, Mark A., Joseph Sanders, and Debra S. Kalmuss. 1988. Social Science in Court: Mobilizing Experts in the School Desegregation Cases. Madison: University of Wisconsin Press.

Cooper, Joel, and Isaac M. Neuhaus. 2000. The "Hired Gun" Effect: Assessing the Effect 
of Pay, Frequency of Testifying, and Credentials on the Perception of Expert Testimony. Law and Human Behavior 24:149-71.

Cooper, Joel, Elizabeth A. Bennett, and Holly L. Sukel. 1996. Complex Scientific Testimony: How Do Jurors Make Decisions? Law and Human Behavior 20:379-94.

DeWitt, John S., James T. Richardson, and Lyle G. Warner. 1997. Novel Scientific Evidence and Controversial Cases: A Social Psychological Examination. Law and Psychology Review 21:1-23.

Diamond, Shari Seidman, and Jonathan D. Casper. 1992. Blindfolding the Jury to Verdict Consequences: Damages, Experts, and the Civil Jury. Law and Society Review 26: 513-63.

Faigman, David L., and A. J. Baglioni. 1998. Bayes' Theorem in the Trial Process. Law and Human Behavior 12:1-17.

Finkel, Norman S., Kristen H. Meister, and Deirdre M. Lightfoot. 1991. The Self-Defense Defense and Community Sentiment. Law and Human Behavior 15:585-602.

Follingstad, Diane R., Darlene S. Polek, Elizabeth S. Hause, Lenne H. Deaton, Michael W. Bulger, and Cynthia D. Conway. 1989. Factors Predicting Verdicts in Cases Where Battered Women Kill Their Husbands. Law and Human Behavior 13:253-69.

Goodman, Jane, Edith Greene, and Elizabeth F. Loftus. 1985. What Confuses Jurors in Complex Cases. Trial (November):65-68.

Gross, Samuel R. 1990. Data on the Use of Expert Witnesses in California Civil Trials. Typescript.

—_. 1991. Expert Evidence. Wisconsin Law Review 1991:1113-232.

Gross, Samuel R., and Kent D. Syverud. 1996. Don't Try: Civil Jury Verdicts in a System Geared to Settlement. UCLA Law Review 44:1-64.

Guthrie, C., Jeffrey J. Rachlinski, and Andrew J. Wistrich. 2001. Inside the Judicial Mind. Cornell Law Review 86:777-830.

Hans, Valerie P. 2000. Business on Trial: The Civil Jury and Corporate Responsibility. New Haven, Conn.: Yale University Press.

Hans, Valerie P., and William S. Lofquist. 1994. Perceptions of Civil Justice: The Litigation Crisis Attitudes of Civil Jurors. Behavioral Sciences and the Law. 12:181-96.

Huber, Peter. 1991. Galileo's Revenge: Junk Science in the Courtroom. New York: Basic Books.

Jacoubovitch, M. Daniel, Gordon Bermant, Geraldine T. Crockett, William McKinley, and Alan Sanstad. 1977. Juror Responses to Direct and Mediated Presentations of Expert Testimony. Journal of Applied Social Psychology 7:227-38.

Kalven, Harry Jr. and Hans Zeisel. 1966. The American Jury. Chicago: University of Chicago Press.

Kassin, Saul M., Lorri N. Williams, and Courtney L. Saunders. 1990. Dirty Tricks of Cross-Examination. Law and Human Behavior 14:373-84.

Kovera, Margaret Bull, Robert J. Levy, Eugene Borgida, and Steven D. Penrod. 1994. Expert Testimony in Child Sexual Abuse Cases. Law and Human Behavior 18:65374.

Krafka, Carol, Meghan A. Dunn, Molly Treadway Johnson, Joe S. Cecil, and Dean Miletich. 2002. Judge and Attorney Experiences, Practices, and Concerns Regarding Expert Testimony in Federal Civil Trials. Psychology, Public Policy, and Law 8:309-32.

Landsman, Stephan, and Richard F. Rakos. 1994. A Preliminary Inquiry into the Effect of Potentially Biasing Information on Judges and Jurors in Civil Litigation. Behavioral Sciences and the Law 12:113-26.

Linz, D., and Steven D. Penrod. 1982. The Use of Experts in the Courtroom. In Social Psychology, ed. Steven D. Penrod. Englewood Cliffs, N.J.: Prentice Hall.

Marshall, Catherine, and Gretchen B. Rossman. 1989. Designing Qualitative Research. Newbury Park, Calif.: Sage Publications. 
Memon, Amina, and Daniel W. Shuman. 1998. Juror Perception of Experts in Civil Disputes: The Role of Race and Gender. Law and Psychology Review 22:179-97.

Nisbett, Richard E., and Lee Ross. 1980. Human Inference: Strategies and Shortcomings of Human Judgment. Englewood Cliffs, N.J.: Prentice Hall.

Saks, Michael J., and Roselle L. Wissler. 1984. Legal and Psychological Bases of Expert Testimony: Surveys of the Law and of Jurors. Behavioral Sciences and the Law 2:43549.

Sanders, Joseph. 1993. Jury Deliberation in a Complex Case: Hauner v. Merrell Dow Pharmaceuticals. Justice System Joumal 16:45-48.

Sanders, Joseph, Shari S. Diamond, and Neil Vidmar. 2002. Legal Perceptions of Science and Expert Knowledge. Psychology, Public Policy, and Law. 8:139-53.

Schklar, Jason, and Shari S. Diamond. 1999. Juror Reactions to DNA Evidence: Errors and Expectancies. Law and Human Behavior 23:159-84.

Schuller, Regina A. 1990. The Impact of Battered Woman Syndrome Testimony on Jury Decision Making: Lavallee v. R. Considered. Windsor Yearbook of Access to Justice 10:105-26.

Schuller, Regina A., and Neil Vidmar. 1992. Battered Woman Syndrome Evidence in the Courtroom: A Review of the Literature. Law and Human Behavior 16:273-91.

Selvin, Molly and Larry Picus. 1987. The Debate over Jury Performance: Observations from a Recent Asbestos Case. Santa Monica, Calif.: Rand Corporation.

Shuman, Daniel W., and Anthony Champagne. 1997. Removing the People from the Legal Process: The Rhetoric and Research on Judicial Selection and Juries. Psychology, Public Policy, and the Law 3:242-58.

Shuman Daniel W., Anthony Champagne, and Elizabeth Whitaker. 1996a. Assessing the Believability of Expert Witnesses: Science in the Jurybox. Jurimetrics Journal 37:2333.

- 1996b. Juror Assessments of the Believability of Expert Witnesses: A Literature Review. Jurimetrics Journal 36:371-82.

Shuman, Daniel W., Elizabeth Whitaker, and Anthony Champagne. 1994. An Empirical Examination of the Use of Expert Witnesses in the Courts-Part 2: A Three City Study. Jurimetrics Journal 34:193-208.

Smith, Brian C., Steven D. Penrod, Amy L. Otto, and Roger C. Park. 1996. Jurors' Use of Probabilistic Evidence. Law and Human Behavior 20:49-82.

Strauss, Anselm L. 1987. Qualitative Analysis for Social Sciences. Cambridge, England: Cambridge University Press.

Thompson, William C., and Edward L. Schumann. 1987. Interpretation of Statistical Evidence in Criminal Trials: The Prosecutor's Fallacy and the Defense Attorney's Fallacy. Law and Human Behavior 11:167-87.

Tiersma, Peter M. 1999. Legal Language. Chicago: University of Chicago Press.

Vidmar, Neil. 1994. Are Juries Competent to Decide Liability in Tort Cases Involving Scientific/Medical Issues? Some Data from Medical Malpractice. Emory Law Journal 43:885-911.

-1995. Medical Malpractice and the American Jury: Confronting the Myths about Jury Incompetence, Deep Pockets, and Outrageous Damage Awards. Ann Arbor: University of Michigan Press.

Vidmar, Neil, and Shari S. Diamond. 2001. Juries and Expert Evidence. Brooklyn Law Review 66:1121-80.

Vondergeest, Lynelle, Charles R. Honts, and Mary K. Devitt. 1993. Effect of Juror and Expert Witness Gender on Jurors' Perceptions of an Expert Witness. Modern Psychological Studies 1:1-6. 